\title{
Peran infografis sebagai media promosi dalam pemanfaatan perpustakaan
}

\author{
Ajeng Resnatika ${ }^{1}$, Sukaesih ${ }^{2}$, Nuning Kurniasih ${ }^{3}$ \\ 1,2,3Program Studi Ilmu Perpustakaan, Universitas Padjadjaran \\ Jl. Raya Bandung-Sumedang Km. 21, Jatinangor, Sumedang, Jawa Barat, 45363 \\ E-mail: ${ }^{1}$ ajengresna@gmail.com, ${ }^{2}$ sukaesih@unpad.ac.id, ${ }^{3}$ nuningkurniasih@yahoo.com
}

Received: January 2018; Accepted: December 2018; Published: December 2018

\begin{abstract}
Infographics are visualizations of data, ideas, information or knowledge through charts, graphs, schedules, and others so that data, ideas, information or knowledge can be presented more than just text and have a visual impact that is quite strong and more interesting. The study was conducted at the Bandung Institute of Technology Library and was aimed to determine the role of infographic's attractiveness, clarity, and ease of understanding in utilizing library services at the Bandung Institute of Technology Library. This study used a quantitative descriptive analysis method, and the population in this study was library visitors totaling 13,716 people. Samples were obtained using the random sampling technique with a total of 100 people. The results of this study indicated that infographics as a promotional medium played a role in library utilization with indicators namely infographic attractiveness, clarity, and ease of understanding. The conclusions are that infographics play a role as promotional media in library utilization: seen from the aspect of attraction, the presentation of content on infographics attract the attention of the reader with display of colors and images that attract to users; from the aspect of clarity, the information presented is precisely the content on the infographics for readers with font and the suitability the image; from the aspect of ease of understanding, the reader easily understand the information contained in the infographics so the reader can interpret for the meaning the message in this infographics.
\end{abstract}

Keywords: Infographic; Academic library; Library promotion media; Library services.

\begin{abstract}
Abstrak
Infografis merupakan visualisasi data, gagasan, informasi atau pengetahuan melalui bagan, grafik, jadwal, dan lainnya agar data, gagasan, informasi atau pengetahuan tersebut dapat disajikan lebih dari sekedar teks dan memiliki dampak visual yang cukup kuat dan lebih menarik. Penelitian ini bertujuan mengetahui peran daya tarik, kejelasan infografis, dan kemudahan untuk memahami dalam pemanfaatan pelayanan perpustakaan di Perpustakaan Institut Teknologi Bandung. Metode yang digunakan dalam penelitian ini adalah metode analisis deskriptif kuantitatif dengan populasi dalam penelitian ini adalah pengunjung perpustakaan berjumlah 13.716 orang. Teknik random sampling yang digunakan berjumlah 100 orang. Penelitian ini dilakukan di Perpustakaan Institut Teknologi Bandung. Hasil dari penelitian ini menunjukkan bahwa infografis sebagai media promosi berperan dalam pemanfaatan perpustakaan. Dengan indikator penelitian yaitu daya tarik, kejelasan infografis, kemudahan dipahami. Maka dari hasil penelitian dapat ditarik simpulan bahwa infografis sebagai media promosi memiliki peran dalam pemanfaatan perpustakaan: dilihat dalam aspek daya tarik dapat disimpulkan bahwa penyajian konten-konten yang ada pada infografis menarik perhatian pembaca infografis melalui tampilan warna dan gambar sehingga menarik minat pembaca; dilihat dari aspek kejelasan, informasi yang disajikan dalam konten-konten infografis memberikan kejelasan pada pembaca melalui tampilan huruf dan kesesuaian gambar yang digunakan; dari aspek kemudahan, pembaca infografis dapat memahami informasi dalam infografis dengan mudah sehingga pembaca dapat memahami makna pesan dan dapat menginterpretasikannya.
\end{abstract}

Kata kunci: Infografis; Perpustakaan perguruan tinggi; Media promosi perpustakaan; Layanan perpustakaan. 


\section{PENDAHULUAN}

Menurut undang-undang No. 43 tahun 2007 tentang perpustakaan dalam pasal 1, disebutkan bahwa,

"Perpustakaan perguruan tinggi merupakan unit pelaksana teknis yang bersama-sama dengan unit lain melaksanakan tri dharma perguruan tinggi melalui menghimpun, memilih, mengolah, merawat serta melayankan sumber informasi kepada Lembaga induk khususnya dan masyarakat akademis pada umumnya" (Kementrian Pendidikan dan Kebudayaan, 2007).

Perpustakaan perguruan tinggi sebagai lembaga informasi dan pusat pengetahuan di lingkungan akademik akan selalu berusaha menyajikan informasi yang relevan dan terbaru. Hal ini bertujuan untuk memberikan layanan dan fasilitas dalam memenuhi kebutuhan informasi penggunanya. Namun, perpustakaan harus mempromosikan keberadaan dan layanan yang dimilikinya agar dapat dimanfaatkan penggunanya.

Promosi layanan yang dimiliki sebuah perpustakaan sangatlah penting karena selain untuk memberitahu pentingnya keberadaan perpustakaan, pengguna perpustakaan diharapkan dapat mengetahui tentang cara menggunakan dan memanfaatkan berbagai fasilitas perpustakaan dengan baik dan benar. Promosi perpustakaan perlu dilakukan dalam rangka meningkatkan optimalisasi penggunaan terhadap layanan yang disediakan sehingga fungsi perpustakaan sebagai pusat informasi dapat berjalan optimal. Upaya promosi yang dapat dilakukan salah satunya adalah dengan menyediakan layanan infografis. Penggunaan media infografis dalam promosi perpustakaan merupakan tindakan transfer informasi dari teks ke bentuk desain grafis yang efektif. Infografis adalah representasi visual dari sebuah informasi, data atau ilmu pegetahuan dalam bentuk grafis. Infografis menjadikan informasi yang rumit dapat dengan singkat dan jelas divisualisasikan dalam grafis sehingga informasi tersebut mudah dipahami oleh pemustaka, yang menjadikan infografis sebagai salah satu media untuk mempromosikan perpustakaan.

Barnes (2017) menjelaskan bahwa, " $A n$ infographic is a graphical composition that consists of data visualizations, headlines and secondary typography, and imagery that provides a visual explanation of newsworthy phenomena such that a general audience can come to a robust understanding and interpretation of the phenomena". Infografis merupakan data visual yang bertujuan memberikan informasi dari suatu fenomena. Masyarakat yang membaca infografis dapat belajar menginterpretasikan makna terhadap isi infografis tersebut.

$\begin{array}{ccr}\text { Infografis } & \text { bertujuan } & \text { untuk } \\ \text { memberitahukan, } & \text { menghibur } & \text { atau }\end{array}$ memberitahukan, menghibur atau mengajak, pembaca atau audiensnya. Infografis memiliki banyak tujuan, yang tergantung infografis apa yang dibuat dan untuk siapa infografis itu dibuat, seperti kata De Haan, Kruikemeier, Lecheler, Smit, and Van der Nat (2017) bahwa, "Picture of the usefulness of information visualizations in the news, and contribute to a growing literature on alternative ways of storytelling in journalism today". Di dunia jurnalistik, gambar yang memuat informasi bertujuan menginformasikan informasi terbaru. Hal ini meningkatkan teknik membaca seperti mendongeng bagi pembaca. 
Berdasarkan rujukan ini, infografis merupakan informasi yang dikemas dalam bentuk visual, bertujuan mempermudah orang untuk mengingat dan memahami sebuah informasi tanpa harus membaca teks panjang. Kita terkadang malas untuk membaca teks atau informasi yang panjang. Infografis dikemas sedemikian rupa agar menghasilkan sebuah informasi bagi pembacanya, yang biasanya terdiri dari teks, gambar, ilustrasi, yang digabungkan lalu melahirkan sebuah informasi baik cetak atau yang berupa digital.

Miftah, Rizal, dan Anwar (2016) menyatakan bahwa,

"Penggunaan infografis telah banyak dilakukan dalam penyajian informasi, hal ini dikarenakan infografis dapat menyederhanakan informasi yang sifatnya begitu kompleks menjadi informasi yang dapat dengan mudah dipahami, infografis juga mampu menarik perhatian berbagai macam kalangan masyarakat, penerapan informasi dalam bentuk infografis juga memiliki keunggulan karena dapat dengan mudah diingat".

Infografis dibuat bertujuan untuk mengkomunikasikan berbagai pesan yang semula begitu kompleks menjadi lebih sederhana, menarik perhatian dan mudah dipahami masyarakat. Selain itu, infografis dapat menjelaskan data lebih mudah dan dapat memonitor secara periodik setiap parameter perubahan.

Perpustakaan Institut Teknologi Bandung (ITB) merupakan perpustakaan perguruan tinggi dengan pemustaka yang berasal dari mahasiswa S1, S2, S3 dan masyarakat umum, terdapat 4 lantai di perpustakaan ITB. Pada lantai 1 terdapat koleksi cadangan buku baru serta koleksi kerjasama. Di lantai 2 terdapat jenis koleksi tahap persiapan bersama (TPB) serta koleksi mingguan. Pada lantai 3 terdapat jenis koleksi mingguan, koleksi rujukan, koleksi jurnal cetak dan kliping. Di lantai 4 terdapat koleksi umum, koleksi kusus dan koleksi langka. Dari semua lantai perpustakaan ini, hanya pada lantai 1 yang terdapat 5 infografis mengenai layanan perpustakaan.

Penyajian media infografis di Perpustakaan ITB merupakan sumber pengetahuan baru bagi pemustaka. Pemustaka mendapat informasi dari layanan bimbingan pemusataka dan humas perpustakaan melalui infografis mengenai layanan perpustakaan. Pemustaka dapat membaca dan memahami informasi yang terdapat dalam infografis agar mempermudah pemustaka yang sedang kebingungan serta menambah pemahaman pemustaka tentang informasi seputar layanan perpustakaan. Penyajian infografis di perpustakaan ITB dikemas untuk menarik perhatian pemustaka dengan sebuah berita, informasi atau data. Terdapat lima buah infografis di UPT Perpustakaan ITB. Infografis pertama berjudul, "Prosedur Peminjaman dan Pengembalian Koleksi", infografis kedua berjudul, "Jadi Anggota Perpustakaan Yuk!, infografis ketiga berjudul, "Ayo Akses DIGILIB", infografis keempat berjudul, "Waktu Operasional Layanan", dan infografis kelima berjudul, "Mau tahu akses e-journal dan e-book?".

Infografis pertama ini berjudul, "Prosedur Peminjaman dan Pengembalian Koleksi", yang menggunakan ilustrasi gambar buku dan terdapat keterangan mengenai jenis koleksi berapa lama buku bisa dipinjam, batas pinjam serta denda untuk keterlambatan pengembalian. 
Latar infografis pertama ini berlatar pink kuning biru. Tulisan dalam judul memakai tanda baca tanya, untuk mengajak para pemustaka mengetahui tata cara peminjaman dan pengembalian buku. Ukuran infografis A3 disesuaikan agar bisa terpajang di mading dan disimpan dimonitor lobi. Posisi infografis ini tepat di lobi dekat pintu masuk perpustakaan.

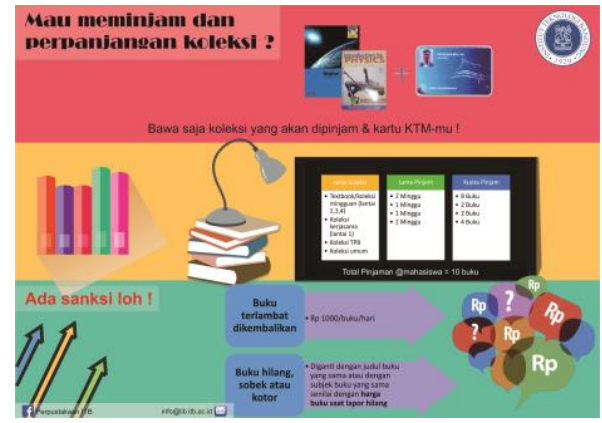

Gambar 1. Infografis pertama

Sumber : Dokumentasi penelitian, 2017

Infografis kedua ini berjudul "Jadi Anggota Perpustakaan Yuk!. Infografis ini sama dengan infografis pertama, yakni dominan menggunakan ilustrasi menggunakan kartun. Warna yang digunakan dominan warna biru, judul menggunakan tanda seru untuk mempertegas pemustaka untuk menjadi anggota perpustakaan.

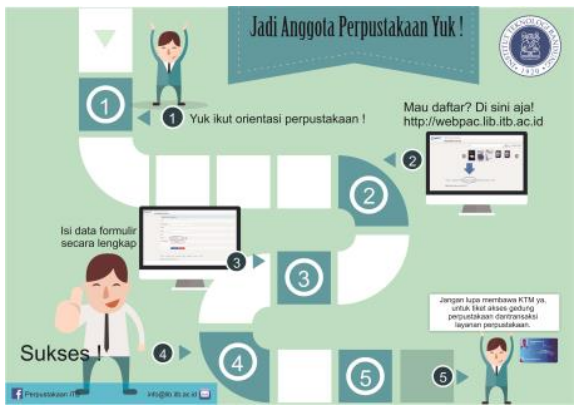

Gambar 2. Infografis kedua

Sumber : Dokumentasi penelitian, 2017

Infografis ketiga berjudul "Ayo akses DIGILIB.", pada infografis ini dominan teks tata cara akses DIGILIB. Lalu hanya terdapat alamatnya web perpustakaan dalam gambar komputer sebagai ilustrasinya, dan latar infografisnya didominasi warna biru.

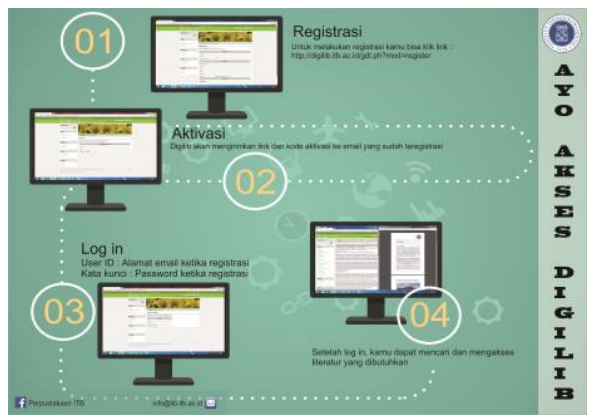

Gambar 3. Infografis ketiga

Sumber : Dokumentasi penelitian, 2017

Infografis keempat berjudul "Waktu operasional layanan". Pada infografis ini menjelaskan waktu jam layanan istirahat serta lokasi dan jumlah lantai perpustakaan. Isi pesan ditulis dalam dua bahasa dan menggunakan latar warna dominan berwarna biru.

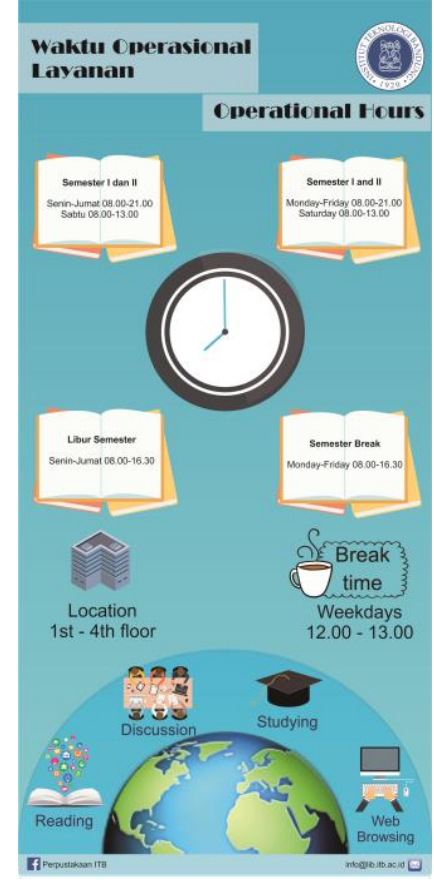

Gambar 4. Infografis keempat

Sumber : Dokumentasi penelitian, 2017

Infografis kelima berjudul "Mau tahu akses e-journal dan e-book?". Dalam infografis ini menggunakan warna biru tua yang lebih dominan dan terdapat warna ungu. Serta tertera tata cara dalam 
mengakses e-journal dan e-book dengan baik.

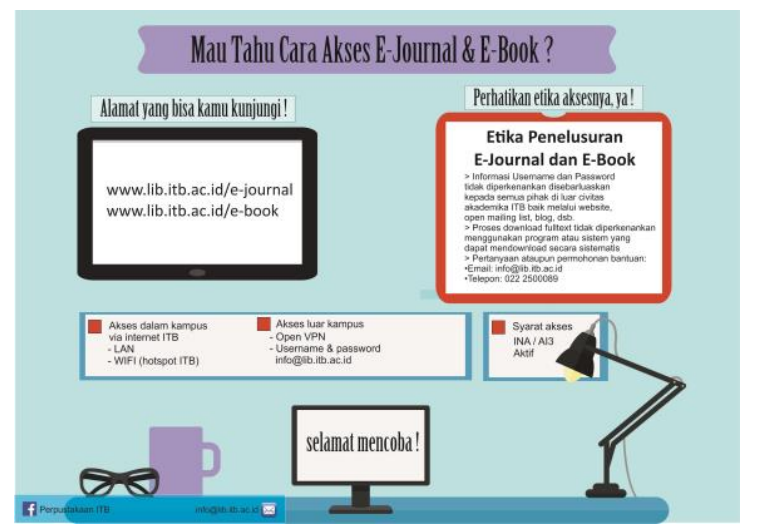

Gambar 5. Infografis kelima

Sumber : Dokumentasi penelitian, 2017

Dalam memproses sebuah informasi secara visual, otak kita akan lebih cepat memproses informasi bahkan sampai 60.000 lebih cepat dari pada teks yang kita baca, dan kebanyakan orang akan meningat $20 \%$ dari apa yang ia baca. Dari fakta di atas bisa kita ketahui bahwa informasi visual lebih mudah diingat oleh otak kita, karena setengah dari otak kita akan mempersembahkan untuk fungsi visual dan $90 \%$ informasi yang terpancar ke otak adalah visual. Otak kita menyiapkan ruang yang banyak untuk visual, karena itu visual mudah untuk diingat kembali dan cepat diproses oleh otak kita.

Schoffelen et al. (2015) mengatakan bahwa melalui visualisasi akan menambah daya tarik suatu infografis. Walaupun satu visualisasi yang dihadirkan berbeda dalam satu infografis maka akan memiliki makna yang sama. Kita akan tertarik terhadap bentuk visual tersebut karena format yang dihadirkan efisien, menawan, dan mampu menghibur. Namun, kita tidak akan suka dengan teks atau artikel yang panjang. Hal ini berbeda ketika kita memandang sebuah tampilan multimedia yang menyajikan informasi yang sama dan tentunya akan lebih menarik. Kita mungkin akan mencerna lebih efisien dan memudahkan memahami melalui visualisasi.

Sebuah infografis memiliki karakter tersendiri yang mampu menarik pembaca yaitu adanya gambar, ilustrasi, grafik dan data yang lebih mendominasi dari pada teks yang dipadukan sedemikian rupa sehingga menjadi sebuah informasi yang menarik bermanfaat dan mudah diingat. Infografis didesain agar dapat dapat memberitahukan informasi, dan mengajak pembaca untuk mengetahui sesuatu.

Tergantung apa yang akan disampaikan kepada pembaca-nya dan kepada siapa infografis tersebut tujuan ditujukan. Sudakov, Bellsky, Usenyuk, and Polyakova (2015) menceritakan dalam penelitiannya bahwa infografis cocok diterapkan di kelas pengajaran siswa sekolah. Secara pedadogik, infografis menghadirkan tampilan yang menarik perhatian siswa, dalam menghadirkan tema yang baru sehingga siswa dapat cepat menjawab pertanyaan.

Penelitian mengenai penggunaan infografis pernah dilakukan pula Bouquin and Epstein (2015), di mana infografis digunakan oleh pustakawan untuk mempromosikan program-program perpustakaan rumah sakit. Selain itu penelitian sejenis pun dilakukan Crane (2016) dalam Sweeper (2017), yakni bagaimana representasi informasi visual, data, pengetahuan perpustakaan diolah menjadi infografis oleh pustakawan.

Berdasarkan penelitian-penelitian di atas, para peneliti menganalisis infografis sebagai media pembelajaran di masyarakat. Dalam penelitian yang penulis teliti, mengenai peran infografis sebagai media promosi dalam pemanfaatan di Perpustakaan ITB. Penelitian ini penting dilakukan untuk dapat menambah kajian di bidang 
perpustakaan terkait penggunaan infografis dalam mempromosikan perpustakaan untuk mengoptimalkan pemanfaatan dari sebuah perpustakaan.

Berdasarkan pemaparan di atas, penelitian ini dirancang untuk menjelaskan dan menggambarkan bagaimana peran infografis dalam pemanfaatan Perpustakaan di Perpustakan ITB, dengan melihat aspek daya Tarik, kejelasan, dan kemudahan pemahaman infografis sebagai media promosi terhadap pemanfaatan perpustakaan di ITB.

\section{METODE PENELITIAN}

Jenis penelitian ini adalah kuantitatif deskriptif. Objek penelitian dilakukan di Perpustakaan Institut Teknologi Bandung Jalan Ganesha No 10 Kota Bandung. Penelitian ini dilakukan selama 6 (enam) bulan dari bulan Januari hingga Juni 2017.

Populasi dari penelitian ini yaitu pengunjung Perpustakaan ITB yang jumlahnya diambil dari total rata-rata pengunjung perpustakaan ITB pada 3 bulan terakhir berjumlah 13.716 orang.

Penentuan sampling menggunakan teknik probability sampling dengan kategori simple random sampling. Simple random sampling digunakan bila seluruh anggota populasi memiliki kesempatan yang sama untuk menjadi sampel, dan peneliti telah memiliki kerangka samplingnya (Sugiyono, 2013). Penentuan jumlah sampel menggunakan rumus Yamane sehingga dari hasil perhitungan populasi diperoleh total sample sejumlah 100 responden. Sebagian besar responden adalah mahasiswa semester II (dua) karena pemustaka yang sering memanfaatkan perpustakaan adalah mahasiswa-mahasiswa TPB dengan jumlah responden laki-laki sebanyak 53 orang $(53 \%)$ sedangkan perempuan sebanyak 47 orang (47\%).

Teknik Pengumpulan Data yang digunakan adalah, 1) kuisioner (angket) merupakan instrumen utama yang berisi sejumlah pertanyaan yang diisi secara sadar oleh responden yaitu pemustaka perpustakaan ITB dan berjumlah 28 item pertanyaan, 2) observasi, peneliti mengumpulkan data dengan mencatat berbagai informasi yang mereka saksikan selama penelitian, 3) studi pustaka, melalui mengkaji berbagai sumber pustaka baik elektronik maupun tercetak, 4) wawancara. Sugiyono (2013) mengatakan bahwa wawancara digunakan sebagai, “Teknik pengumpulan data apabila peneliti ingin melakukan studi pendahuluan atau menemukan permasalahan yang harus diteliti".

Teknik analisis data menggunakan analisis data deskriptif yang meliputi, 1) analisis data responden, 2) analisis data penelitian, 3) analisis katagori jawaban, dan 4) analisis tabulasi silang. Selain itu peneliti juga menggunakan analisis pearson product moment yang ditunjukkan untuk menganalisis hubungan sebab akibat antara variable independent $(\mathrm{X})$ dengan variable dependent $(\mathrm{Y})$. Untuk Uji validitas, item variabel peran infografis $(X)$ dan pemanfaatan layanan perpustakaan (Y) dinyatakan bahwa semua item valid karena memiliki koefisien validitas lebih dari 0.3. Nilai koefisien validitas berkisar antara 0.668 dan 0.973 . Terkait uji realibilitas menggunakan koefisien realibilitas Alpha Cronbach. Koefisien reliabilitas variabel pada peran infografis (X) dan pemanfaatan layanan perpustakaan $(\mathrm{Y})$ di atas 0.7 sehingga dinyatakan reliabel. 


\section{HASIL DAN PEMBAHASAN}

Penelitian mengenai peran infografis sebagai media promosi dalam pemanfaatan perpustakaan, memiliki sampel sebanyak 100 orang. Peneliti menyebarkan kuisioner yang terdiri dari 28 item pertanyaan. Hasil penelitian diuraikan dalam bentuk tabel distribusi frekuensi. Hasil perhitungan untuk kategori setiap sub variabel dan variabel dalam angket penelitian terdapat dalam tabel 1.

Berdasarkan tabel 1, jawaban responden pada item-item mengenai daya tarik yaitu dalam kategori sangat setuju sebanyak 451 orang, kategori setuju 514 orang, dan kategori netral 32 orang. Dengan demikian, responden cenderung menjawab daya tarik dalam kategori tinggi. Dengan skor 4413 yang termasuk kategori sangat tinggi pada rentang 42005000. Hal ini menunjukan bahwa daya tarik infografis di Perpustakaan ITB sangat berperan.

Infografis merupakan salah satu cara dalam menyampaikan sebuah informasi, agar menarik orang yang membacanya. Infografis yang ada pada perpustakaan ITB cukup memberikan daya tarik bagi pemustaka, informasi telah dikemas dengan bentuk yang berbeda, agar memudahkan pemustaka memahami sebuah informasi. Infografis yang didukung dengan adanya ilustrasi, desain, warna, dan teks dipadukan agar menarik dan memudahkan pemustaka dalam memahami sebuah informasi yang ingin disampaikan.

Dunlap and Lowenthal mengatakan bahwa,

"Visuals have the potential to be an efficient, precise, and clearer way to communicate than oral and text alone. Visuals also can assist with cognitive processing by providing a context or metaphor. When visuals are used effectively, they serve to help people understand abstract, complicated, and complex information, especially when people are unfamiliar with the concept and do not have a pre-existing mental model to assist with the comprehension of new information. Therefore, we are all visual learners".

Dikatakan bahwa informasi secara visual dalam infografis merupakan komunikasi yang lebih baik daripada komunikasi verbal atau tatap muka. Infografis secara visual menggunakan metaphor, untuk membantu pembaca memahami pesan dari infografis tersebut, khususnya bagi pembaca pemula infografis untuk menjadi pembelajar bidang visual.

Infografis memiliki daya pikat visual yang bagus. Seseorang yang membaca infografis dapat dengan mudah memahami informasi yang disampaikannya dibandingkan dengan membaca full text.

Sesuai tabel 2, bahwa jawaban responden pada item-item mengenai kejelasan infografis yaitu dalam kategori sangat setuju sebanyak 239 orang, kategori setuju 310 orang, dan kategori netral 49 orang. Dengan demikian, responden cenderung menjawab kejelasan infografis dalam kategori tinggi. Skor 2586 yang termasuk kategori sangat tinggi pada rentang 2530-3000. Hal ini menunjukan bahwa kejelasan infografis di perpustakaan ITB sangat berperan.

Infografis di perpustakaan masih kurang jelas dengan ukuran yang masih kecil sehingga tidak terlalu terlihat jika dilihat dari kejauahan, ukuran sebuah infografis akan lebih efektif jika memiliki ukuran yang lebih besar. Kejelasan huruf, gambar dan poster merupakan hal yang perlu dalam sebuah infografis. Infografis 
harus memuat tulisan yang jelas agar orang mudah membaca dan melihat informasi yang ada pada infografis tersebut.

Ada 201 alfabet yang lalu dikembangkan oleh Caslon (1730) and Baskerville (1757) dalam Cassedy (2018), yang menjadi pijakan beberapa perusahaan dalam memproduksi karya huruf (typrfoundy) dengan memperhatikan kejelasan (legibility), keterbacaan (readibility), dan kesederhanaan bentuk huruf (simplicity) tersebut. Pemilihan huruf ternyata mampu menggambarkan pesan yang akan disampaikan pada pembaca (Cassedy, 2018; Schoffelen et al., 2015).

Moeller (2013) dalam Gormley and McDermott (2015) menambahkan, bahwa untuk memudahkan pembaca membaca isi pesan infografis, maka ukuran huruf pun harus diperhitungkan sesuai ukuran infografisnya. "They are asked whether they can find more information in the image; this encourages them to reexamine the image for additional and deeper information, much like they do when closely reading alphabetic text" (Gormley \& McDermott, 2015).

Berdasarkan tabel 3, jawaban responden pada item-item mengenai kemudahan dipahami yaitu dalam kategori sangat setuju sebanyak 144 orang, kategori setuju 329 orang, dan kategori netral 26 orang, tidak setuju 1 orang. Dengan demikian, responden cenderung menjawab kemudahan dipahami dalam kategori tinggi. Dengan skor 2116 yang termasuk kategori sangat tinggi pada rentang 2100-2500. Hal ini menunjukan bahwa kemudahan infografis di Perpustakaan ITB sangat berperan.

Kita sering mendengar seseorang mengaku lebih mudah belajar visual. Berarti sederhananya mereka perlu melihat sesuatu agar dapat memahaminya. Sebuah infografis akan mudah dipahami jika didukung oleh informasi salah satunya. "Infographics can help students process information more quickly, and can be used in a variety of formats. Many libraryrelated infographics already exist online and can be incorporated into a lesson [.....]. They can be used as handouts to provide general information about the library and library services [...]" (Johns, 2014). Pembaca, misalnya siswa-siswi sekolah atau mahasiswa melalui infografis dapat secara cepat memahami informasi yang terkandung di dalamnya. Bahkan beberapa perpustakaan menggunakan infografis sebagai media bimbingan pemustaka.

Smiciklas (2012) dalam Kibar and Akkoyunlu (2017), menjelaskan, "An infographic is the 'visualization of data or ideas that tries to convey complex information in a manner that can be quickly consumed and easily understood to an audience". Infografis menggambarkan data atau ide yang berbentuk informasi yang kompleks menjadi sederhana bagi pembaca. Hal ini untuk memudahkan pembaca untuk memahami isi pesan.

Informasi dalam infografis tidak hanya disampaikan dalam bentuk teks saja, tapi bisa berupa konsep desain yang memberikan sebuah informasi bagi pembacanya. Di mana agar informasi tersebut dapat dipahami oleh pembacanya maka harus ada gambaran jelas tentang informasi yang disampaikan.

Dalam infografis, tulisan yang didukung oleh gambar, grafik atau foto menjadikan informasi yang ingin disampaikan lebih mudah untuk dipahami oleh pembacanya. Infografis di Perpustakaan ITB memberikan kemudahan dalam memahami pembacanya, dari penggunaan bahasa dan 
kalimat yang mudah dipahami dan infomasi yang disampaikan bisa dimengerti oleh pembaca, dan bahasa yang ringan dan jelas.

Selain itu, untuk melengkapi isi infografis maka dapat ditambahkan statistic grafis. "In the absence of a simple general rule of infographics design that could be used to improve all statistical graphics forevermore, it would still be useful to get concrete examples of how to improve upon poorly designed statistical plots. Perhaps the infographics community would be prepared to educate the statistical graphics community one plot at a time" (Murrell, 2013).

Infografis yang menggunakan statistik grafis, harus mampu diuraikan melalui kalimat pada pembaca. Di dalamnya harus dijelaskan atau digambarkan melalui kalimat yang jelas. Dengan demikian, melalui infografis menjadi media pembelajaran bagi pembaca untuk berpikir kognitif, bisa membaca lalu menganalisanya.

Berdasarkan tabel 4, menunjukkan bahwa jawaban responden pada item-item mengenai media promosi yaitu dalam kategori sangat setuju sebanyak 834 orang, kategori setuju 1153 orang, dan kategori netral 107 orang. Dengan demikian, responden cenderung menjawab peran infografis sebagai media promosi dalam kategori tinggi, dengan skor 9115 yang termasuk kategori sangat tinggi pada rentang 8820-10500. Hal ini menunjukan bahwa peran infografis sebagai media promosi di perpustakaan ITB sangat berperan.

Berdasarkan tabel 5., jawaban responden pada item-item mengenai kemudahan dipahami yaitu dalam kategori sangat setuju sebanyak 176 orang, kategori setuju 212 orang, dan kategori netral 11 orang, tidak setuju 1 orang. Dengan demikian, responden cenderung menjawab pemanfaatan layanan perpustakaan dalam kategori tinggi. Melalui skor 1763 yang termasuk kategori sangat tinggi pada rentang 1680-2000. Hal ini menunjukan bahwa pemanfaatan perpustakaan di perpustakaan ITB sangat berperan.

Menurut kamus Kamus Besar Bahasa Indonesia (KBBI) menyatakan bahwa, “Kata 'pemanfaatan' berasal dari kata 'Manfaat' artinya faedah, sedangkan pemanfaatan artinya suatu proses cara, perbuatan memanfaatkan" (Kementrian Pendidikan dan Kebudayaan, 2016).

Fungsi perpustakaan perguruan tinggi, antara lain: 1) Fungsi edukasi guna mendukung pencapaian tujuan pembelajaran, pengorganisasian bahan pembelajaran sivitas akademika.; 2) Fungsi pusat informasi. Diharapkan perpustakaan dapat memenuhi kebutuhan informasi sang pemakai (user).; 3) Fungsi riset/penelitian, perpustakaan perguruan tinggi diharapkan dapat mendukung pelaksanaan riset yang dilakukan oleh sivitas akademika.; 4) Fungsi rekreasi, perpustakaan berfungsi sebagai tempat rekreasi dengan cara menyajikan koleksi yang menghibur pembaca; 5) Fungsi publikasi perpustakaan selayaknya juga membantu melakukan publikasi karya yang dihasilkan sivitas akademik dan katya non akademik.; 6) Fungsi deposit perpustakaan menjadi pusat deposit untuk seluruh karya dan pengetahuan.; 7) Fungsi interprestasi melalui publikasi kajian dan memberikan nilai tambah terhadap sumber-sumber informasi yang dimiliki perpustakaan (Berawi, 2012).

Berdasarkan pendapat di atas, dapat disimpulkan bahwa pada dasarnya tujuan perpustakaan perguruan tinggi adalah mendukung kinerja dari perguruan tinggi dalam menyelenggarakan pendidikan 
dengan menyediakan sumber-sumber informasi ilmiah di perpustakaan tersebut dan selalu melayani pengguna (mahasiswa), selama menjalankan pendidikan di perguruan tinggi yang bersangkutan. Agar tujuannya dapat terlaksana, perpustakaan perguruan tinggi harus menjalankan fungsinya dengan baik.

Sesuai tabel 6, tampak bahwa jawaban responden mengenai media promosi dalam kategori tinggi dan pemanfaatan layanan perpustakaan dalam kategori tinggi sebanyak 33 orang (33\%).

Pada tabel 7, tampak bahwa jawaban responden mengenai daya tarik dalam kategori sedang dan pemanfaatan layanan perpustakaan dalam kategori sedang sebanyak 37 orang (37\%). Dapat diketahui hasil tabulasi silang berdasarkan pengkategorian dari variabel daya tarik infografis dengan pemanfaatan perpustakaan memiliki peran yang positif. Mayoritas responden ada pada kategori sedang dengan persentasi sebanyak 37 orang (37\%). Hal ini mengindikasikan bahwa daya tarik infografis memiliki peran positif yang sedang.

Dalam daya tarik, peran infografis sebagai media promosi dalam pemanfaatan perpustakaan dilihat dari aspek daya tarik dapat disimpulkan bahwa penyajian konten-konten yang ada pada infografis menarik perhatian pembacanya sehingga menjadi magnet untuk para pembacanya dalam memanfaaatkan informasi tentang layanan perpustakaan yang ada dalam infografis. Hal tersebut tidak terlepas dari desain infografis yang rapi sehingga menarik untuk dilihat, perpaduan komposisi warna pada infografis yang bervariasi dari warna judul infografis, warna tulisan infografis, warna latar infografis menjadi daya tarik tersendiri bagi pembaca sehingga menjadi sebuah dorongan bagi para pemustaka untuk membaca infografis penambahan informasi seputar layanan Perpustakaan ITB.

Di tabel 8, tampak jawaban responden mengenai kejelasan dalam kategori sedang dan pemanfaatan layanan perpustakaan dalam kategori sedang sebanyak 34 orang (34\%). Hasil tabulasi silang berdasarkan pengkategorian dari variabel kejelasan infografis dengan pemanfaatan perpustakaan memiliki peran yang positif. Mayoritas responden ada pada kategori sedang dengan persentasi sebanyak 34 orang (34\%). Hal ini mengindikasikan bahwa daya tarik kejelasan infografis memiliki peran positif yang sedang.

Peran infografis sebagai media promosi dalam pemanfaatan perpustakaan dilihat dari aspek kejelasan infografis yang mampu menyajikan informasi secara jelas konten-konten yang ada pada infografis untuk pembacanya sehingga menjadi magnet untuk para pembacanya memanfaaatkan informasi tentang layanan perpustakaan yang ada dalam infografis. Hal tersebut tidak terlepas dari desain kejelasan huruf dan ilustrasi infografis, posisi letak infografis, tinggi letak infografis sehingga menjadi sebuah dorongan bagi para pemustaka membaca infografis untuk penambahan informasi seputar layanan perpustakaan ITB.

Berdasarkan tabel 9., tampak bahwa jawaban responden mengenai kemudahan dipahami dalam kategori sedang dan pemanfaatan layanan perpustakaan dalam kategori sedang sebanyak 44 orang $(44 \%)$, 34 orang $(34 \%)$.

Dapat diketahui hasil tabulasi silang berdasarkan pengkategorian dari variabel kemudahan dipahami dengan pemanfaatan perpustakaan memiliki peran yang positif. Mayoritas responden 
ada pada kategori sedang dengan persentasi sebanyak 44 orang (44\%). Hal ini mengindikasikan bahwa kemudahan dipahami infografis memiliki peran positif yang sedang.

Peran infografis sebagai media promosi dalam pemanfaatan perpustakaan dilihat dari aspek kemudahan dipahami dapat disimpulkan bahwa pesan informasi yang terdapat pada infografis mudah dipahami oleh pembacanya. Menggunakan infografis untuk memasarkan konten karena kemudahan dan kecepatan yang dimungkinkan dalam komunikasi. Hal tersebut tidak terlepas dari kemudahan informasi dipahami, kalimat dan bahasa yang mudah dipahami sehingga menjadi sebuah dorongan bagi para pemustaka membaca infografis untuk penambahan informasi seputar layanan perpustakaan ITB.

\section{SIMPULAN}

Infografis sebagai media promosi di Perpustakaan ITB memiliki tiga indikator penelitian, diantaranya daya tarik infografis, kejelasan infografis, dan infografis yang mudah dipahami. Infografis dilihat dari indikator aspek daya tarik, dapat disimpulkan bahwa penyajian konten-konten pada infografis telah menarik perhatian pembacanya melalui tampilan warna dan gambar sehingga infografis menjadi magnet bagi para pembaca untuk memanfaaatkan informasi di layanan perpustakaan. Hal ini tidak terlepas dari desain infografis yang rapi, dilihat dari perpaduan komposisi warna judul infografis, warna tulisan infografis, dan warna latar infografis. Pemustaka sebagai pembaca menjadi terdorong membaca infografis untuk menambah informasi seputar layanan Perpustakaan ITB. Lalu infografis pada aspek kejelasan, yakni informasi dalam infografis berhasil menjelaskan konten-konten dalam infografis pada pembacanya melalui tampilan huruf dan kesesuaian gambar yang digunakan, misalnya desain kejelasan huruf dan ilustrasi infografis, posisi letak infografis, dan letak tinggi infografis. Selain itu, infografis dari segi aspek kemudahan, yakni infografis yang dihadirkan di perpustakaan telah membuat pembaca mudah memahami makna dari pesan yang disampaikan sehingga pembaca dapat menginterpretasikannya. Pustakawan menggunakan infografis sebagai media komunikasi pada pemustaka. Tentunya, infografis yang dibuat telah memperhatikan kesesuaian kalimat yang mudah dipahami pembaca. Walaupun infografis cetak telah banyak digunakan sebagai media promosi di Perpustakaan ITB, kiranya penelitian penggunaan infografis di media sosial dan website Perpustakaan ITB perlu diteliti. Hal ini melihat kecenderungan pemustaka yang sudah menggunakan media sosial dan website sebagai pencarian informasi. Pustakawan perlu merencanakan penyebaran electronic infografis agar semua pemustaka dari internal perpustakaan dan eksternal perpustakaan dapat membacanya.

\section{DAFTAR PUSTAKA}

Barnes, S. R. (2017). Examining the processes involved in the design of journalistic information graphics: An exploratory study. Journal of Visual Literacy, 36(2), 55-76. https://doi.org/https:/ / doi.org/10.1 080/1051144X.2017.1372088

Berawi, I. (2012). Mengenal lebih dekat perpustakaan perguruan tinggi. Jurnal 
Iqra', 6(1), 49-62. Retrieved from http://repository.uinsu.ac.id/690/1/ iqra\%27 2012 vol.06 no. 01 - Copy $\% 287 \% 29 . p d f$

Bouquin, D., \& Epstein, H.-A. B. (2015). Teaching data visualization basics to market the value of a Hospital Library: An infographic as one example. Journal of Hospital Librarianship, 15(4), 349-364. https://doi.org/https:/ / doi.org/10.1 080/15323269.2015.1079686

Cassedy, T. (2018). Types of reading, types of pleasure: Pantographia and the specimens of globalization. Word $\mathcal{E}$ Image:A Journal of Verbal/Visual Enquiry, 34(2), 137-151. https://doi.org/https://doi.org/10.1 080/02666286.2017.1389575

De Haan, Y., Kruikemeier, S., Lecheler, S., Smit, G., \& Van der Nat, R. (2017). When does an infographic say more than a thousand words? Journalism Studies, 19(9), 1293-1312. https://doi.org/https://doi.org/10.1 080/1461670X.2016.1267592

Dunlap, J. C., \& Lowenthal, P. R. (2016). Getting graphic about infographics: Design lessons learned from popular infographics. Journal of Visual Literacy, 35(1), 42-59. Retrieved from http://scihub.tw/https://doi.org/10.1080/105 1144X.2016.1205832

Gormley, K., \& McDermott, P. (2015). Searching for evidence-teaching students to become effective readers by visualizing information in texts. The Clearing House: A Journal of Educational Strategies, Issues and Ideas, 88(6), 171-177. https://doi.org/https://doi.org/10.1 080/00098655.2015.1074878

Johns, E. M. (2014). Creating a colorful classroom: Incorporating multimedia and graphics into library instruction. Internet Reference Services Quarterly, 19(3-4), 255-269. Retrieved from https://doi.org/10.1080/10875301.20 14.984821

Kementrian Pendidikan dan Kebudayaan. Undang-Undang Republik Indonesia nomor 43 tahun 2007 tentang perpustakaan, Pub. L. No. 43 (2007). Indonesia:

http://www.bpkp.go.id/uu/filedow nload/2/36/176.bpkp. Retrieved from

http://www.bpkp.go.id/uu/filedow nload/2/36/176.bpkp.

Kementrian Pendidikan dan Kebudayaan. (2016). KBBI daring. Retrieved from https://kbbi.kemdikbud.go.id/entri/ terbuka

Kibar, P. N., \& Akkoyunlu, B. (2017). Fostering and assessing infographic design for learning: The Development of infographic design criteria. Journal of Visual Literacy, 36(1), 20-40. https:/ / doi.org/https:/ / doi.org/10.1 080/1051144X.2017.1331680

Miftah, M. N., Rizal, E., \& Anwar, R. K. (2016). Pola literasi visual infografer dalam pembuatan informasi grafis (infografis). Kajian Informasi $\mathcal{E}$ Perpustakaan, 4(1), 87-94. Retrieved from

http://jurnal.unpad.ac.id/jkip/article /view/11635/5448

Murrell, P. (2013). InfoVis and statistical graphics: Comment. Journal of Computational and Graphical Statistics, 22(1), 33-37. https://doi.org/https://doi.org/10.1 080/10618600.2012.751875

Schoffelen, J., Claes, S., Huybrechts, L., Martens, S., Chua, A., \& Moere, A. V. (2015). Visualising things: 
Perspectives on how to make things public through visualisation. CoDesign: International Journal of CoCreation in Design and the Arts, 11(34), 179-192. https://doi.org/https://doi.org/10.1 080/15710882.2015.1081240

Sudakov, Bellsky, T., Usenyuk, T., \& Polyakova, V. (2015). Infographics and mathematics: a Mechanism for effective learning in the classroom. PRIMUS: Problems, Resources, and Issues in Mathematics Undergraduate Studies, 26(2), 158-167. https://doi.org/http://www.tandfonl ine.com/action/showCitFormats?doi $=10.1080 / 10511970.2015 .1072607$

Sugiyono. (2013). Metode Penelitian Kuantitatif, Kualitatif dan RED. Bandung: Alfabeta.

Sweeper, D. (2017). Infographics: A practical guide for librarians. Journal of Electronic Resources Librarianship, 29(1),

65-66. https://doi.org/https://doi.org/10.1 080/1941126X.2017.1270113 
